\title{
FEATURES OF 'NENGLISH', AN EMERGING VARIETY OF ENGLISH
}

\author{
A Reflective Journal \\ By \\ Ishwar Koirala \\ MPhil in ELE, Kathmandu University, School of Education
}

\begin{abstract}
English has gained a high value in Nepalese societies. The craze of English Medium Instruction at schools, use of English in government and private offices and adoption of it by Nepalese speaker has shown that English has slowly become our property, our language. As a result we are on the way to develop 'our English' i.e. Nenglish or Nepanglish. This paper excavates and explains the features of Nepali English that is used commonly in Nepal. This article is mainly a desk research which also includes researcher's observation of the English phenomena in the town. The findings show that Nepali English is on the way to being a special variety of English and has several features such as being influenced by 'Hinglish'; utilizing American lexicon; adopting words from Sanskrit language; including special modification and coinage; Nepaliness in pronouncing and adding tag questions etc.
\end{abstract}




\section{Introduction}

Language is a dynamic entity and it gets modified temporally and spatially. When any language crosses its national or cultural borders, and is accepted by its new speakers, it is expected to serve the feelings of its new speakers, too. In such cases the language has to be changed to some extent (Patil, 2018). Because of this tendency of language, English language has developed many forms and varieties. There are noticeable differences between British English, American English and Australian English to name but a few. English, at present is not limited to these varieties, rather, there are Englishes (Kachru, 1985; Kachru, 1990; Filickaya, 2009).

Since English is spoken all over the world, the number of its speakers is increasing significantly. Along with its growing number, its popularity and importance is becoming more intense. Because of its use to a greater extent in countries like Hong Kong, Singapore and India, they have developed unique variety of English which are often referred as Hong Kong English, Singapore English and Hinglish (Indian English) respectively. Karn (2006) argues that because of its adoptable/adaptable nature, English has become hybrid language today and it is assimilated in different regions of the world. In fact, the native speakers of English seem to have lost the standardization mechanism to examine the standard of Englishes (Filickaya, 2009).

English, after being officially introduced in Nepal in 1954 as a medium of instruction, has remained as a significant language. In spite of the fact that the present constitution of Nepal does not say anything about English language (MoLJPA, 2016) English has widely been in practice in the country. Its craze is increasing as growing number of institutional schools and colleges are using it as medium of instruction and even the Nepali medium community schools are adopting English medium instruction. English is considered as a must to find a job in any private and government offices. The local bodies are using English language in addition to Nepali language. In some local government offices like rural municipalities and municipalities, they are using three-language format for their letter pad, for example: the letter pad of Lalitpur Metropolitan City (Lalitpur Metropolitan City, 2021). Documents can be made in all three languages i.e. Nepali, English and Newari there. 
Like Indian, Singaporean and Hong Kong variety of English, one more variety of English is emerging i.e. Nepali variety of English. So much has happened in adopting English as a medium of communication since the time when Rai (2006) claimed Nepali English to be beginning to show the signs of its peculiarities. Nepali English is different from the Standard English on one hand (2006).

This paper explores how English in Nepal has acquired uniqueness. It explains the features of Nepali English. The first part of the paper puts light on a brief history of English and its present status in the country. And the second part deals with the features of English used particularly in Nepal.

\section{English in Nepal: A Brief History}

Historical documents reveal that English was present in Nepal as early as seventeenth century (Giri, 2015). He argues that the Gurkha soldiers who were selected to be in British armies were given trainings in English. However, English language officially entered Nepal with the establishment of the first modern school i.e. Durbar High School in 1854. It was established by the Rana ruler to teach English to the children of Ranas and therefore common people were not given access to it (Awasthi, 2004). The Rana rulers considered English as the sign of development and civilization. Since English language classes were associated to the Ranas, the Shahs and the limited aristocrats, it became the symbol of status, power, and privilege and a means to divide people into the rulers and the ruled (Giri, 2010).

During the Rana regime, there were only few schools in the country and selected elites had access to educate their children. Duwadi (2018) argues that it was only after 1951's political change that education became formally available to general public. He notes that the well-to-do families used to send their children to India prior to that.

They Later Trichandra College which was affiliated to Patna University, India began to teach English to common people, as well (Sharma, 2006). Subsequently, the first university of the country, Tribhuvan University was established in 1959 which gave high priority to its curriculum in English (Duwadi, 2018). The university included English as a compulsory subject in intermediate and bachelor's degree for all faculties. However, 
English flourished dramatically in Nepal after 1990's political change (Shrestha, 2016). Democracy was restored in the country and the schools could be opened privately, too. Private schools mushroomed and they had a vital role in spreading English language in the country (Giri, 2010).

Recently, English language has become one of the prominent parts of Nepalese life. The country has excelled dramatically in science and communication technology among others. Due to the use of social media, English has reached to many of those who are even illiterate. The importance of English has grown also because of Nepali students wanting to acquire international education. The trend of Nepali students going abroad for higher education is increasing every year and English has become very important

\section{Current Status of English in Nepal}

It is estimated that around 2 billion people are learning English at least as a subject and there is hardly any country which does not teach English as school level (Brown, 2018). Similarly, Larsen-Freeman (2007) sees tremendous increase in the demand of English as the trends towards globalization of which Nepal cannot be the exception. According to Kachru's (1985) model, Nepal is in 'the expanding' circle of English language speakers. This circle represents the large linguistic context that includes the countries like Nepal, China, and Korea who treat English as a Foreign Language (EFL) and use extensively. In spite of the fact that Nepal was never politically colonized by Englishmen, English is used extensively in the country (Shrestha, 2016).

English language is compulsory subject from pre-school to university level. In each grade from grade one to grade 12, the students have to read at least one subject English. Tertiary education has been reformatted in Nepal and intermediate degree has been replaced by Grade 11 and 12 of Secondary level school. In institutional schools, medium of instruction is English and most of such schools, English medium environment is specially maintained. All subjects except Nepali, is taught in English.

In university level, all questions (of all subjects except Nepali) in final examination are set in English, although the students can answer either in English or in Nepali. Most subjects like mathematics, engineering, nursing, information technology etc. are taught in 
English medium, only. The questions in public service commission and teacher service commission are written in English and therefore can be answered in English.

English language is associated with prestige in the society. In new Nepal (referred to the country after the promulgation of the new constitution in 2015) the role of English is going to be more prominent and widely spreading in uniting people and strengthening national harmony (Bhattarai \& Gautam, 2007). Brown (2018) relates the importance of English language in South Asian countries with employability. English is not only used as a language of communication but also serves as an important skill that students tend to acquire in order to pursue further education, training and employment.

The trend of people sending their children to institutional schools is growing rapidly throughout the country. And one of the key reasons behind it is the English medium instruction in such institutional/ private schools. Even the community schools with relatively enough manpower are adopting English medium instruction. Khati (2016) argues that government schools have started English medium instruction in order to hold the students in their schools. This trend has impacted on the positive growth and development of English in the country.

In Nepal, English is used in different sectors like schools and colleges, tourism industry, international trades and businesses, media and private offices etc. Pandey, 2020 argues that ground for the use of English became more fertile after the abolition of the monarchy in 2008 after which the nation implemented secularism and inclusive democratic policies. Amazingly, for the first time in the history of Nepal, population census 2011 recorded around 2032 Nepali citizens in the country having English as their mother tongue (CBS, 2014). Duwadi (2018) argues that the rate of English language use will grow further. For him, "the most recent development affecting the spread of English is technological innovation with the widespread introduction of English TV channels, movies and access to the internet." 


\section{Features of Nepali English Lexicon}

Although 'Nenglish' has not been an approved variety of English, a number of scholars have signaled that Nepali English is showing its peculiarity and uniqueness (Rai, 2006). This is often taken as the indication that Nepali flavored English is on its way to emerge. The following are the features of Nepali English (Nenglish).

\section{Influence of Hinglish}

Nepal shares its border with India in three sides. The border is open and therefore Nepalese share innumerable elements with India including language, culture and expertise, let alone trade and business. Nepalese people have very close contact with Indian people. India, being in the 'outer circle' of the speakers of English (Kachru, 1992), number and the proportion of English speakers is higher in India than in Nepal. The open borders, interdependence of people and their regular interaction influences a lot in the language they speak. Indian English obviously influences the variety of English spoken in Nepal. Rai (2006) argues that Nenglish is influenced by and closer to Hinglish.

Hindi cinemas and television programs are very popular among Nepali people. We do learn Hindi and English from those films and telefilms. Hindi cinemas and music has a significant market in Nepal. Indian televisions are commonly watched in Nepali households. A large number of students go to India for further education. And since English is the most common lingua franca and also the official language in several Indian states, it is also used as a medium of communication between Nepali and Indian people.

The words like chapatti, dhoti, lathi, lathi-charge etc. are similar to those used in India. Rai (2006) puts an example of the word 'load-shedding' which is used in Hinglish. The word 'load-shedding' means a state of power cut for a short period purposefully done by electricity board to save energy. He claims that there is no such word in English but this word has been borrowed in 'Nenglish' from 'Hinglish'. Like in Indian English, 'hotel' can mean a 'restaurant' also in Nepali English. The word 'hotel' is used for 'hotel' and 'restaurant' or even for a 'tea-shop' sometimes. We use 'standard' for 'grade/class' (like in 
the expression: In which standard do you read?), 'shift' to mean 'to move into a new house/apartment' etc. (Examples taken from Patil, 2018).

Bollywood movies and Indian TV channels, which are very popularly watched in Nepal, use English language massively. Those movies and television programs are one of the sources from which we learn Indian variety of English. Many things like the way we make tag questions in Nenglish, the way we address people and speak various sounds show that the Nepali English is very close to Hinglish. Sanskrit, Hindi, English and Nepali etc. belong to same linguistic family therefore share a number of words and structures. 'Ma' in Hindi, 'aama' in Nepali, 'mom' in English and 'mata' in Sanskrit is one of the examples. Similarly, 'mahina' in Nepali, 'month' in English, 'mah' in Hindi and 'mas' in Sanskrit are some other examples.

\section{Use of Words from American English}

When English entered Nepal, it was British English because the establishment of first (English) school was the result of the visit of the then prime minister Jang Bahadur Rana to England (Awasthi, 2004). So, the development began from British English. However, while learning and using British English, we also share some words from American English. This is the case in India as well (Sailaza, 2009).

The word 'faculty' in American English is preferred in Nepali universities over the British word 'staff'. Like in Indian universities (Sailaza, 2009), in Nepali universities 'staff' refers to non-teaching staff. But in schools, the word 'staff' refers to 'teachers'. The caption below is picture of the sign board from a secondary school in Hetauda. It is the teachers' room there. In Nepal, the word 'staff' is very popular as referring to the bus crew namely driver, conductor and assistant (khalasi). The motels are often named as '... Staff Hotel'.

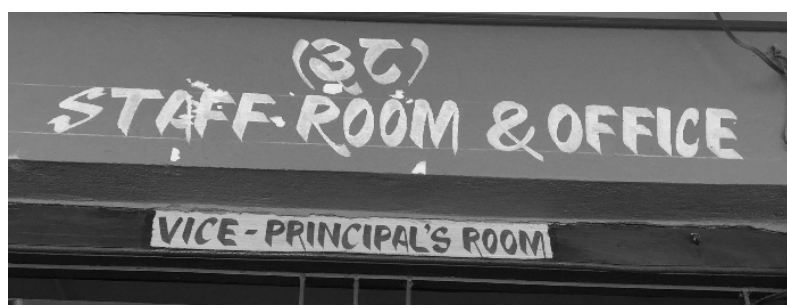


The following are some of the American English words that are used in Nepal:

American words

'Truck' (for 'lorry' in British)

'Purse' (for 'handbag' in British)

'Last name' (for 'surname')

'Diaper' (for 'nappy')

'Apartment' (for 'flat')

'Pharmacy' (for the 'chemist's')

'Program' (for 'programme')

'Vacation' (for 'holiday')

'Liter' (for 'litre')

'Meter' (for 'metre')

'Center' (for 'centre')

These words are comprehensible to both British and Americans but still they are distinguishable on the basis of their origin. In the context of Nepal, people generally do not distinguish them but rather use them interchangeably.

\section{Special Constructions or Coinage}

Some of the English words have been typically constructed in Nepal. The words like 'long toilet' and 'short toilet' to refer respectively to 'excrete' and to 'pee' are a few of them. They are used in schools and colleges and also among people in the cities. Some people also say 'to go for five minutes' to refer to 'go to pee'. These kinds of constructions are often unintelligible to the native speakers but they are frequently used in Nepali contexts.

Rai (2006) further talks about a word 'Dadu' which is used to refer to 'dad' in Nepal. Dad is an English word. The formation of 'dadu' is interesting. In Nepali language, the words 'nani' and 'sani' (polite word to refer to young female child) become 'nanu' and 'sanu' to show more closeness and affection. The words 'Dadu' and 'Mommu' are made from the words 'dad' and 'mom' in the same process. So is the case with the word 'baby' which is used as 'babu' (pronounced as /bebu:/).

There are some specific words that are coined in Nepal. The words like 'yarsa' and 'bhang' are such words. The word 'yarsa' is used for Nepali word 'yarsagumba', a medicinal herb specially found in Mountain region of Nepal and the 'bhang' is a kind of leafy plant which is used as a drug. The words like 'Nepal band' meaning 'a political blockade' or 'strike' are such words. People use the word 'Nepali time' for the condition of 
being late to start something. The kind of following conversation is very common in Nepalese context.

Speaker one: Oh! No! It's been late. The program might have started already.

Speaker two: Oh. Don't worry. It's Nepali time and it's always starts late by one hour. This kind of tendency is satirically referred as 'Nepali time'.

There are some words like 'selfie', 'selfies', 'welfie' 'welfies' which are very common in Nepal. They are not enlisted in the Standard English dictionary yet. These words are believed to have formed in South Korea (The Himalayan Times, May 24, 2018) but they are used very commonly in Nepali English.

The cultures of eating pizza, burger, and talking like Englishmen have been taken as the signs of modernization. Because of the use of new gadgets like oven, mixture, liquid (mosquito liquids) and 'ear phone' or 'head phone' etc. such words have become the words of our tongue. People prefer to say iron instead of 'istiree'. English 'ear phone' is used in Nepali conversation. 'Liquid' for my mother refers to 'a liquid used to avoid mosquito' but nothing else.

\section{Words from Nepali Culture}

In each culture, there are special words or phrases which may not have exact word in other language. There are some in Nepali culture which do not have English equivalent. Such words are generally constructed by using more than one word. The words like 'ricefeeding' ceremony, 'sacred-thread', maternal-home, daal-bhaat-tarkari, tika, puja, aarti etc. are taken from Nepali. These words are used in some cultural practices in Hindu communities.

Patil (2018) stresses that people with no knowledge of new variety of English may find it incomprehensible. He gives the examples from Indian context like there are a number of words added by Indian users of English for instance: 'pre-pone' to mean the opposite of 'post-pone', 'co-brother' for 'wife's sister's husband', 'optical' for 'glasses' etc. These words are used in the same way in Nepali context, too. Like in Indian counting system, we also have special counting system and Nepali English speakers often use this system. In Nepali system 'lakh' is used for 'one hundred thousand' and 'crore' for 'ten 
million'. Counting system in Nepali goes like: one, ten, hundred, thousand, ten thousand, lakh, ten lakh, crore ...while in Standard English, it goes like: one, ten, hundred, thousand, ten thousand, hundred thousand, million, ten million, hundred million...

There are some words used same in Nepali and they are also used same in Standard English. The words like 'yoga', 'karma', 'guru', 'dharma' etc. are of this category. The word Namaste is often used in Nepali English. Many also use the words like 'good morning' and 'good night' but as they want to bring the feel of the 'wish', they use word the special Nepali word 'Namaste'.

\section{Nepali Modification of Some English Words}

There are many English words which are spoken differently by common Nepalese people. My father is not a literate person, however he uses some words like 'tyam' for 'time' and 'fine' for 'fan'. In fact, these words are very commonly spoken in town and cities in Nepal. The following are such words which are spoken differently in Nepal.

\begin{tabular}{|l|l|l|l|}
\hline English Words & Nepali Use & English words & Nepali Use \\
\hline Colonel & Karnel & Lieutenant & Laptan \\
\hline Lantern & Laltin & Cement & Semanti \\
\hline Battery & Betary & Tank & Tankie \\
\hline Bulb & Bull & Copy & Kapi \\
\hline Fan & Fine & Time & Tyam \\
\hline History & Histry & Heartily & heartly \\
\hline Truck & Tadak & & \\
\hline
\end{tabular}

My grandmother cannot read and write Nepali, let alone English. However, she uses the English word 'tension' when she is worried about something. 'Ta halla nagar, aaphulai kasto tension bhako chha.' [Do not make a noise, I have a tension.] The word 'bro' for brother is used very commonly in Nepali context. Regardless of the academic status of the people, they are found to be using these words.

In most of the meat shops in the town and cities, we see a board with the words '...Fresh House'. Very few of them write '...Flesh House'. It is supposed to be 'Flesh House' to refer to 'meat shop'. People might have written 'Fresh House' for 'Flesh House' 
by mistake. But when I asked some of them, they said they intentionally wrote 'fresh house' because they wanted mean that their products are always fresh, not stale. But I have found a shop of fresh fruits and juice shop with the name 'Fresh house'. Some of them do not know why they did so. They did so as they saw similar boards somewhere else. I doubt someone used 'fresh' by mistake for 'flesh' and many others just copied.

\section{Nepaliness in the Use of Tag}

In spoken Nepali, we have a peculiar way of making tag question. People say ' $M a$ garchhu, hunna ra?', 'Ram janchha, hoina ra?' etc. This effect is seen when they speak English. Like in Hinglish, (Sailaza, 2009) 'isn't it?' or 'no' is used as question tag in Nepalese context.

He is coming, isn't it? [It should be 'isn't he']

She was intelligent, isn 't it? [It should be 'wasn't she']

In Standard English the tag questions vary on the basis of sentence structure. In the cases above the real tag question should be different than the one used by people. So, there is trend of using same tag structure for all types of English sentences. Similarly, like Indian English, 'no' is often used as a tag question. A student asked me, 'Come, no, sir?' It is like 'Come, will you, sir?' But we can see this as deviation from Nepali language itself. In Nepali language the word ' $n a$ ' is used as a special word called 'nipat'. They are not meaningful words on their own but they are used in sentences to bring certain meaning of the sentences. The sentence like 'Aau na aau' or 'Jau na jau' [equivalent to 'please, come' or 'please, go']. The sentences like 'Khela na' (Do play) or 'Bhana na' (Do speak/say) are some common patterns of expression in Nepali. It seems like such word ' $n a$ ' is used to bring such meaning while speaking English, as well.

\section{Special Way of Addressing People}

Being spoken in Nepal or by Nepali people, English language undoubtedly includes particular words or the way they are used. There is one word 'jee' which is often used by Nepalese English speakers. The expression like 'Laxman Jee' or 'Sapkota Jee' is often used to show the respect. 
The word 'Miss' is used to refer to 'an unmarried lady' whereas 'Madam' is used to refer to 'a married woman' in many cases in Nepali context. Men use the word 'My Mrs.' to refer to his 'wife'. However, the women hardly use the word 'My Mr.' to refer to their 'husband'. Like in Indian English (Sailaza, 2009) words like 'sir' and 'miss' or 'madam' is used with different subject teachers. They use 'Science sir', 'Math Miss' or 'Geography madam' instead of using their names.

The words like 'maternal uncle', 'maternal home' are very commonly used in Nepali English. In Standard English they do not distinguish between 'maternal' and 'paternal' for uncle. The brother of mother or father both are uncle. But they are taken as different in Nepalese culture. So the words are used accordingly. Similarly the words like 'big brother/sister' or sometimes 'elder-brother/sister' are used to refer to older brother/sister, and small brother/sister or sometimes 'younger brother' to refer to younger brother/sister.

\section{Nepaliness in Pronunciation}

Speakers of new varieties of English insert a sound, delete a sound, substitute a sound, and rearrange sounds when they pronounce certain words. Moreover, they use deviant word stress patterns (Patil, 2018, p. 1).

Some patterns of pronunciation are different in Nepali English than in Standard English. Long vowels and short vowels are pronounced in the same way by Nepalese speakers. The effect might be from the tendency of Nepalese people speaking Nepali in such a way. They speak long/i:/ and short/I/ in the same way. Normally, Nepali speakers do pronounce sit/sit/ and seat/si:t/ in the same way. Similarly, Nepalese speakers do not distinguish between / $/ /$ and $/ \mathrm{u}: /$ and such effect can be seen in their English pronunciation. They pronounce the vowel sound of 'put' /pot/ and 'shoot'/fu:t/ in the same way.

Similarly Nepalese speaker pronounce the sounds $/ \mathrm{s} /$ and $/ \mathrm{J} /$ in the same way. For them the consonant sound of 'see' /si:/ and 'she' / fi/ is same. 


\section{English Everywhere}

Observing the sign boards in the town, I have found that there is hardly any board that does not contain English words. Only very few firms or stores have written their names in purely Nepali words. I found two kinds of trends there. First, there are many containing English words but written in Devnagari font. They contain one or few such words. Second, there are others with completely English words which are written in English alphabets.

The way English words are used in almost all sign/hoarding boards of the service has proven that we are getting closer to adopt English as our medium of communication. It also shows how English has assimilated itself into our culture and our everyday activities.
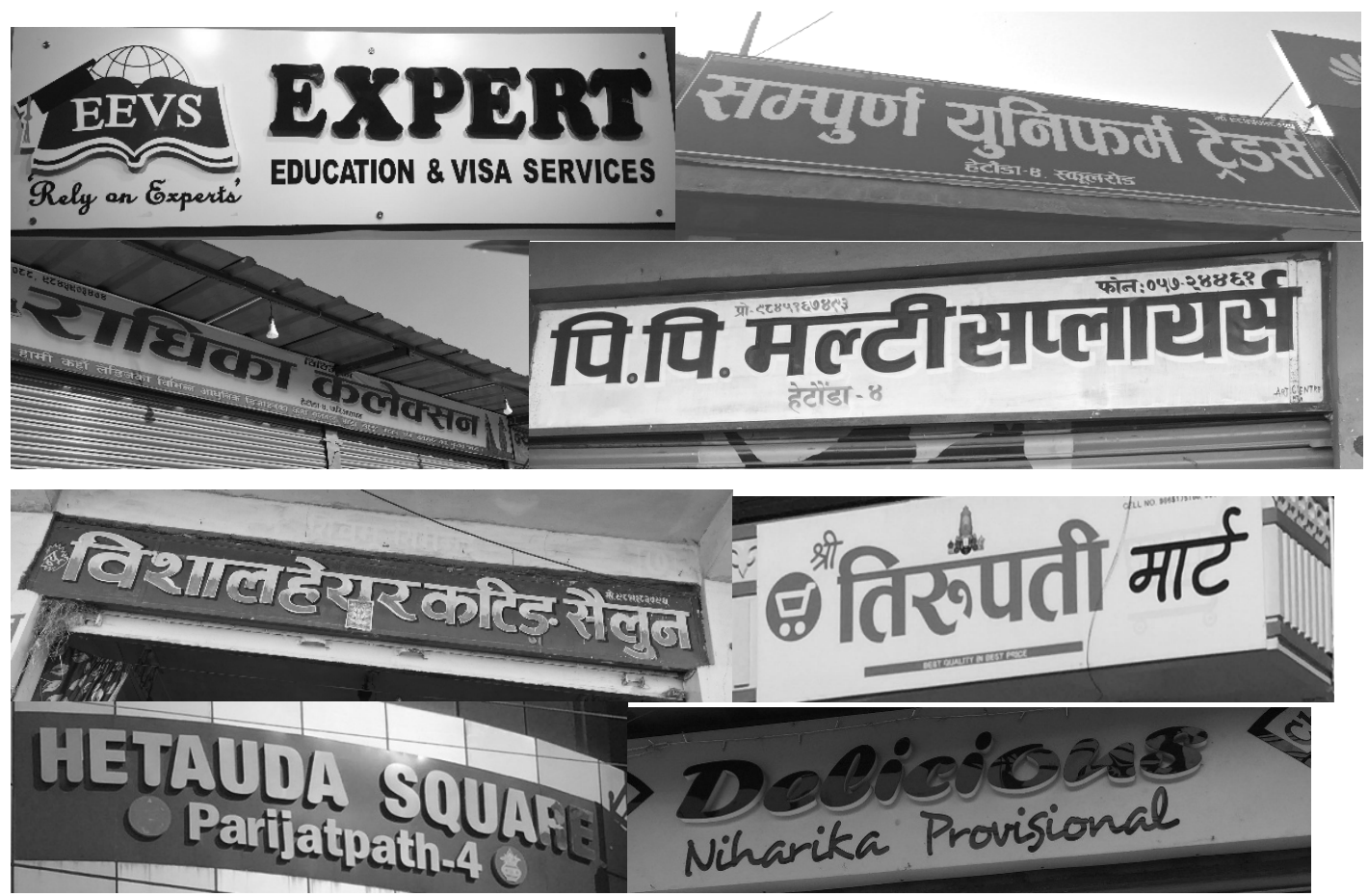

The above collection shows how we encounter English words in our daily life. The names of shops and stores are in English and so are the products found there. In the above collection, P. P. Multi-suppliers has been written in Devnagari font. They have written the name in the same way in their letter pad, too. In the next context, I enquired the barber in the saloon (Bishal Hair Cutting Saloon) why he wrote it English. He replied that he has not used English word. According to him, this name is in Nepali language because he has 
written in Nepali (Nepali alphabets). Each citizen visiting the town encounter such English words and this trend has reached in the villages, too.

Nepali names like Sita, Gita, Ram and Mohan etc. are rarely given to their children nowadays. Rather, when a baby is born, most people try to find English names for their children. One of my friends has given the name 'Success' to his son. Similarly, the other friend's son is called 'Summer'. My own daughter's name is 'Eva'. Some people have used the proper names from English communities like Peter, Harry, Darwin and John etc. There is another trend that they use English pronunciation but with different spellings (the pronunciation is like that of an English word). I have a student whose name is 'Sijan' (pronounced as English 'season'). The names like 'Mansun' (pronounced as the word 'Monsoon'), Ritham (as rhythm), Parsyut (as pursuit) are very common as the names of young children.

Many have named the places with English words like China Quarter, Chapali Height, Hong Kong Bazaar, New Road, Tharu Village, Pun Hill, T. CN Road, Paras Buspark, High School Road, Campus Gate etc. People use English Names to the institutions like schools, colleges etc. Naming them like The Texas International School, Cambridge Study Center, Next Term Consultancy, Expert Education and Visa services, Morgan International etc. has been in the trend.

\section{Conclusion}

Like in many other countries, English is being more and more popular in Nepal. The reasons like the status it is given (though unannounced), the prestige it is associated with and its flexible nature have made way to its wide use and assimilation in Nepalese society. English language has been widely accepted in Nepal and because of its use and assimilation, it is showing uniqueness in its form.

This desk research has come to a conclusion that Nepali English is on the way to being Nenglish, a variety of English. It has got various features. First, English spoken in Nepal is heavily influenced by Indian variety of English. Nepali speakers of English share words from American English and also from Sanskrit language. Some words are also coined, some taken fro Nepali culture and some modified. Nepali style of using tag 
question, pronouncing certain sounds and addressing people have been the property of Nepali English nowadays. And English, being very widely used by Nepali people, have become an unavoidable part of our daily life. Growing use of English in the country due to various reasons, and its assimilation in the local culture has paved way to developing a new variety of English in Nepal.

\section{References}

Awasthi, L. D. (2004). Exploring monolingual school practices in multilingual Nepal. $\mathrm{PhD}$ Dissertation, Danish University of Education, Copenhagen, Denmark.

Bhattarai, G. R. \& Gautam, G. R. (2007). The proposed ELT survey: Redefining status and role of English in Nepal. Journal of NELTA, 12(1-2), 32-36.

Brown, R. (2018). English and its roles in education: Subject of medium of instruction? In D. Hayes (Ed.) English language teaching in Nepal: Research, reflection and practice (pp: 13-34). Kathmandu: British Council.

CBS. (2014). Statistics pocket book of Nepal. Thapathali, Kathmandu, Nepal: Central Bureau of Statistics.

CBS. (2014). National Population and Housing Census 2011: Social characteristics tables. Kathmandu, Nepal: National Planning Commission Secretariat, Central Bureau of Statistics, Government of Nepal.

Davis, K. A. \& Phyak, P. (2017). Engaged language policy and practices. New York: Routledge (Taylor and Francis Group).

Duwadi, E. P. (2018). Historical developments in the teaching and learning of English in Nepal. In D. Hayes (Ed.) English language teaching in Nepal: Research, reflection and practice (pp: 179-185). Kathmandu: British Council.

Filickaya, F. (2009). World Englishes, English as an international language and applied linguistics. English Language Teaching, 2(3), 35-38.

Giri, R. A. (2010). Cultural anarchism: The consequences of privileging languages in Nepal. Journal of Multilingual and Multicultural Development, 31(1), 87-100.

Kachru, B. B. (1985). Standards, codification, and sociolinguistic realism: The English language in the outer circle. In: Quirk, R. and H. Widdowson, (eds.) English in the World: Teaching and Learning the language and the literature. Cambridge: Cambridge University Press. 
Kachru, B. B. (1992). The other tongue: English across cultures. Urbana, Illinois: University of Illinois Press.

Karn S. K. (2006). English: Then, now and in the days ahead. Journal of NELTA, 11(1-2), 73-79.

Khati, A. R. (2016). English as medium of instruction: My experience from a Nepali hinterland. Journal of NELTA, 21 (1-2), 23-30.

Lalitpur Metropolitan City (2021). Archived on $31^{\text {st }}$ July, 2021 from https://lalitpurmun.gov.np/en

Larsen-Freeman, D. (2007). Teaching and Learning English from ideology to empowerment. Journal of NELTA, 12(1-2), 67-74.

MoLJPA, (2016). Constitution of Nepal (First Amendment). Kathmandu: Ministry of Law, Justice and Parliamentary Affairs, Government of Nepal.

Pandey, S. B. (2020). English in Nepal: A sociological profile. World Englishes, 1-14 [John Wiley \& Sons Ltd]

Patil, Z. N. (2018). New varieties of English: Issues of incomprehensibility and unintelligibility. Journal of NELTA, 1-13.

Rai, V. S. (2006). English, Hinglish and Nenglish. Journal of NELTA, 11(1-2), 34-39.

Ranabhat, M. B. \& Chiluwal, S. B. (2018). The spread of English as a medium of instruction in Nepal's community schools. In D. Hayes (Ed.) English language teaching in Nepal: Research, reflection and practice (pp: 81-106). Kathmandu: British Council.

Sailaza, P. (2009). Dialects of English: Indian English. Edinburgh: Edinburgh University Press.

Sharma, K. C. (2006). English in Nepal from the past to the present. Journal of NELTA, 11(1-2), 24-33

Shrestha, S. (2016). Role and status of English and other languages in Nepal. Journal of NELTA, 21(1-2), 105-112.

The Himalayan Times. (2018). Various issues from May, 15 to May, 25). Published by International Media Network, Kathmandu, Nepal. 